\title{
Studies about Blood Pressure of Toxemias of Late Pregnancy.
}

\author{
First Report.
}

\begin{abstract}
A Statistical Observation on Blood Pressure of Gravida and Parturient, especially of Toxemias of Late Pregnancy.
\end{abstract}

By

\section{Rin Hikichi. \\ (引地 偷)}

(From the Department of Obstetrics and Gynecology of Tohoku University, Sendai. Director: Prof. T. Shinoda.)

(Received for publication, December 13, 1949)

Although several authors have reported about blood pressure of gravida, the papers about that in progress of pregnancy, especially from the first half term are very rare. For its normal highest limit, Yogo" decided on $130 \mathrm{~mm} . \mathrm{Hg}$ (systolic), more than Hashizume's ${ }^{2} 127$ which he had found in the last term of pregnancy.

In foreign lands, the highest for normal limits is 160 (Krönig), the lowest 120 (Zangemeister) and yet unsettled.

Therefore because there have been no criteria for the so-called " danger zone" of blood pressure, I hoped statistically to investigate the systolic blood pressure, above all, of toxemias, from the first half term of pregnancy to termination of delivery and to confirm the "danger zone."

\section{Materials and articles of examination.}

Gravidas and parturients who had been admitted into the Tohoku University Hospital for the 3 year period from 1943 to 1945, and whose date of expectancy were in this period......2879 out-patients and 2024 inpatients.......were investigated. Toxemias of these were 376 out-patients and 383 in-patients.

Taking systematically each month of pregnancy, the first stage of delivery, and right after the placental stage, I looked for "mode" of systolic blood pressure. Furthermore concerning blood pressure changes during labor, 111 parturients were observed in 1944.

My criteria for toxemia is as follows: After the 7th month of pregnancy (1) Hypertension over $150 \mathrm{~mm} . \mathrm{Hg}$, (2) Albuminuria over $0.5 \%$ (Esbach), (3) Edema beyond the lower abdominal region and (4) two or all of these symptoms. 
Furthermore I devided toxemias in 2 groups, namely hypertensives and non-hypertensives.

Results (Fig. 1.) and discussion.

\section{(1) Normal gravidas.}

In the later half term, Yogo stated, some $40 \%$ had shown a tendency to increase, $18 \%$ to decrease, ${ }^{-17} \%$ no constant tendency and $25 \%$ was unchangeable. The difference between the age-groups was hard to find, he decided on 130 for a physiological limit. Strassmann ${ }^{3)}$ investigated 230 gravidas after the 7 th month of pregnancy, and found in $48 \%$ a rise over $10 \mathrm{~mm}$. in the last trimester. If there were not pathological finding in urine, he stressed, blood pressure below 150 might be normal.

Besides Hashizume pointed out a more or less increasing tendency after the 6th month of pregnancy.

In my results also, from the frequency distribution table (omission), cases over 131 markedly reduced, the modes are far lower and up to the 9 th month no tendency to a rise was noticed. Namely from the 4th to the 9th month, the modes are between 101 and 105 and have no constant tendency, but coming to the 10th month they increase slightly but not extremly.

In the first stage of labor, 111 viz. a rise of 5 to $10 \mathrm{~mm}$. above each

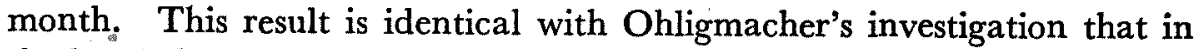
the last 2 days of pregnancy blood pressure increases $5 \mathrm{~mm}$. and then with the onset of labor 5 to $10 \mathrm{~mm}$. more. Right after delivery it is 110 , nearly same as the first stage. So-called old primiparas (over 31 years old) give no high figure either.

From the first half term of pregnancy to termination of labor, generally speaking, by either age-groups or parity-groups, (arithmetic) means just rarely go beyond 120 , with no case over 130 .

(2) Toxemias of late pregnancy.

Unfortunately, R. G. Douglas") mentioned, the vast majority of the toxemias of pregnancy are associated with a hypertension. Seitz reported that gravidas with blood pressure of over 150 frequently developed eclampsia and pre-eclampsia, and then Hashizume settled for a danger zone the hypertension of over 150, because in 4 eclamptic patients the average of the systolic pressure was 161 . Besides Dieckmann ${ }^{5}$ ) had classified systolic blood pressure of 140 or more for 2 days or longer as a toxemia, although without any other toxemic symptoms.

At present in America, 140 is generally allowed to be a boundary between normal and toxemic gravida, but as described, I will accord with our provisional definition and later examine these figures.

a. Non-hypertensives (concerning one or both of edema and albuminuria). 
Up to the 9th month, the means are almost the same as those of normal gravidas, but in the 10th month they are slightly higher. In the first stage of labor it is 124 or slightly higher.

b. Hypertensives (with or without edema and albuminuria). The modes from the 5th to the 9th month are between 111 and 116 , have no constant tendency, and are $10 \mathrm{~mm}$. higher than normal, but in the 10th month 143 , viz. a rise of some $30 \mathrm{~mm}$. In the first stage 148, and right after delivery 136 , therefore indicating a relative quick recovery after delivery.

Ohligmacher's $\mathrm{s}^{6)}$ conclusion, that a rise of 30 to $40 \mathrm{~mm}$. during labor indicates a serious lesion, may be applicable here, too.

The evidence, that through all the terms of pregnancy and delivery the modes are not as high as expected, may be because of pressure lability, on which I will touch in the next papers. Accordingly it must be wrong to diagnose toxemias by only one reading of blood pressure.

c. Eclampsia and pre-eclampsia. If investigating eclampsia and preeclampsia only, up to the 6th month no high figure was seen, and from the 7 th to the 10th month the means are between 146 and 149. In the first stage a rise of $30 \mathrm{~mm}$. (viz. 186) occurs, and right after delivery it returns to 162. Primiparas of these have a rise two month before delivery, and in the first stage also less increasing than multiparas.

(3) The highest systolic blood pressure during labor.

Even in the rest periods of pains, Ohligmacher and Doerr described, a rise of 5 to $10 \mathrm{~mm}$. in the stage of dilatation, and of $5 \mathrm{to} 10 \mathrm{~mm}$. more in the stage of expulsion were usual, and also the average increase through the whole term of labor was $18 \mathrm{~mm}$.

From my results, in normal parturient the mode is $12 \mathrm{~mm}$. higher and in general toxemia $8 \mathrm{~mm}$. higher than the first stage of labor, especially in multiparas of the latter this rise is greater.

In brief, both normals and toxemias, as a rule, have a rise of about $10 \mathrm{~mm}$. after the onset of labor.

In consideration of these results, for a normal limit of blood pressure I càn not help deciding on 140, and supporting Dieckmann's classification. But for it after the onset of labor, 150 may be thought good.

\section{Conclusions.}

From my investigation of blood pressure of 2879 gravidas and 2024 parturients, $I$ arrived at the following conclusions.

1) Normal gravidas. Up to the 9 th month no remarkable change noticed, the modes are between 101 and 105. In the 10th month a slight increase of blood pressure and in the first stage of labor a rise of 5 to $10 \mathrm{~mm}$., thence forth during labor a rise of about $10 \mathrm{~mm}$. more again are remarked, and right after delivery being same as the first stage of labor. 


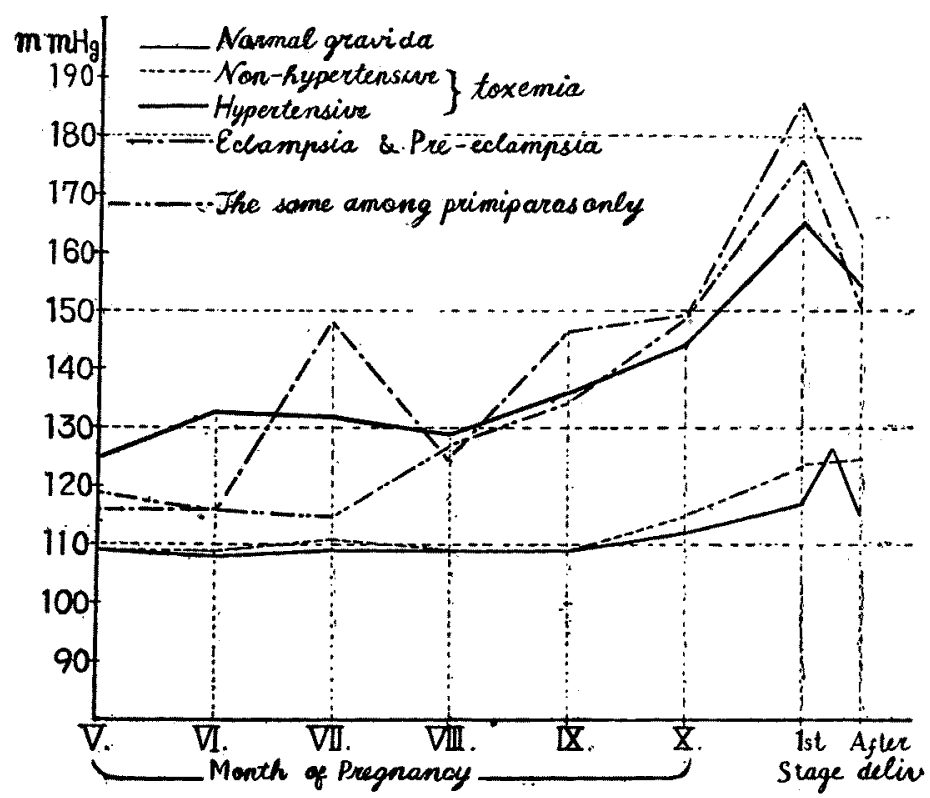

Fig. 1. Curves are plotted from arithmetic means.

By both the age- and the parity-groups no significant difference was admitted, and so-called old primiparas had no high figure.

2) Toxemias. Non-hypertensives, almost being same as normals, only in the first stage the pressure increase was more marked a little than the latter.

In hypertensives, up to the 9 th month the modes are between 111 and 116 , only $10 \mathrm{~mm}$. higher than normals, but in the 10 th month 143 (a rise of about $30 \mathrm{~mm}$.), in the first stage 148, right after delivery 136, indicating a relative quick recovery. Generally toxemias, as a rule, have a rise of about $8 \mathrm{~mm}$. more along with labor progress. In cases of eclampsia and pre-eclampsia, since the 7 th month are markedly increasing. Up to the 10 th month the means are nearly 150, in the first stage 186 and right after delivery 162. Primiparas of these have a tendency to a rise after the 8 th month.

3) During the whole term of pregnancy a normal limit of blood pressure may be decided to be $140 \mathrm{~mm}$. $\mathrm{Hg}$, but after the onset of delivery it is $150 \mathrm{~mm}$. $\mathrm{Hg}$.

About blood pressure up to the 10th month of pregnancy, I can not help but support Dieckmann's classification in which 140 or more for 2 days or longer is admitted into toxemias. 


\section{References.}

1) Yogo, Kinki Sanka Huzinka Kiyo, 1939, 22, 1250 and 1465.

2) Hashizume, Nippon Huzinka Gk. Z., 1928, 23, 472.

3) Strassmann, Arch. f. Gynäk., 1929, 136, 345.

4) Douglas, Amer. J. Obst. and Gynec., 1937, 34, 565.

5) Dieckmann, Amer. J. Obst. and Gynec., 1938, 36, 798.

6) Ohligmacher, Zbl. f. Gynäk., 1935, 59, 1154. 